\title{
La utilización de material audiovisual para el acceso a los conocimientos previos en el aprendizaje de Geografía e Historia
}

The use of audio-visual material for accessing prior knowledge in Geography and History learning

Nora Ramos Vallecillo, Víctor Murillo Ligored, Alfonso Revilla Carrasco (*)

\section{Resumen}

En el presente estudio se realiza un análisis sobre la efectividad de los recursos audiovisuales en la clase de Geografía e Historia, en primer ciclo de la Educación Secundaria Obligatoria. El método de t rabajo ha s ido c ualitativo, incluyendo c omo her ramientas de doc umentación las entrevistas individuales semiestructuradas al alumnado y observación del trabajo de aula, con anotaciones en el cuaderno de campo. Las herramientas audiovisuales facilitan el incremento de c omprensión, ac tivación de c onocimientos pr evios, at ención y $\mathrm{m}$ otivación, ya qu e transforman algunos $\mathrm{c}$ ontenidos que $r$ esultan a burridos en al go $\mathrm{m}$ ás at ractivo $\mathrm{p}$ ara el alumnado. Los propios estudiantes así lo valorany, por ello, consideran más útil la introducción de los temas a través de estos recursos debido a su naturaleza gráfica y dinámica.

Palabras Clave: Geografía e Historia, recursos audiovisuales, conocimientos previos, secundaria, aprendizaje.

\begin{abstract}
This study analyses the effectiveness of aud iovisual resources in the Geography and History class in the first cycle of high s chool. The working m ethod has bee $n$ qualitative, including as documentation t ools: $s$ emi-structured i ndividual i nterviews $w$ ith $s$ tudents a nd observation of classroom $w$ ork, $w$ ith $n$ otes in the $f$ ield $n$ otebook. A udiovisual tools $f$ acilitate an increase in understanding, activation of prior knowledge, attention and motivation, as they transform some content that is boring into something more attractive for the students. The students themselves value this and, therefore, consider the introduction of the topics through these resources to be more useful due to their graphic and dynamic nature.
\end{abstract}

Key words: Geography and $\mathrm{H}$ istory, au diovisual r esources, pr ior k nowledge, high s chool, learning.

\section{Introducción}

Nos encontramos en un momento de ca mbio que radica en t omar conciencia de l a importancia que su pone poner I a a tención en I a i nteracción que se produce en e I proceso de apr endizaje del alumnado, en el método (Caeiro et. al., 2021) y el diseño de si tuaciones contextuales que Io faciliten (Espinar y Vigueras, 2020). Para que el

* Universidad del Zaragoza (España), Ramos, N. (0000-0002-4524-7459). Murillo, M. (ORCID 0000-0001-6829-1738). Revilla, A. (ORCID 0000-0002-0832-649X). • Autora de correspondencia: Ramos, noramos@unizar.es.

Ramos Vallecillo, N.; Murillo Ligored, V. y Revilla Carrasco, A. (2021).La utilización de material audiovisual para el acceso a los conocimientos previos en el aprendizaje de geografía e historia.Clio. History and History Teaching, 47, 161-177 https://doi.org/10.26754/ojs clio/clio.2021475706: Recibido 30-06-2021. Aceptado 9/11/2021. 
aprendizaje se produzca es preciso el papel a ctivo de I os est udiantes m ediante el desarrollo de una act ividad mental que posibilite la reelaboración y ampliación de sus esquemas de conocimiento.

Actualmente el alumnado está en co nstante exposición a co ntenidos visuales(García, Tur-Viñes, \& Pastor, 2018). Se puede afirmar que la cultura audiovisual forma parte de las nuevas generaciones de escolares y, sin embargo, nos encontramos todavía con una gran permeabilidad entre la esfera social y escolar (López y De la Caba, 2010). Si estos recursos están presentes en la realidad y en las vidas de los estudiantes los educadores deberían integrarlas en la cotidianidad escolar (Ambrós y Breu, 2011). La incorporación de si tuaciones cercanas a la realidad del alumnado permite la creación de actividades significativas y funcionales.

La escu ela debe a rmonizar I as necesidades sociales desde l a i mplementación de programaciones didácticas capaces de formar en un consumo racional de imágenes (Cislaghi, 2020). El marco de la educación integral de los ciudadanos es un contexto cada vez más tecnológico, cargado de experiencias con los medios de comunicación (Aguaded, 1999; Dewey, 2008). Los centros escolares deben ser el lugar formal para trasmitir usa ndo I a i magen, donde ad quiere $r$ elevancia y $t$ rascendencia ( Lois y Hollman, 2013).

Al introducir recursos audiovisuales como el emento educa dor en el aul a, el modelo didáctico adquiere un punto de vista integrador, abierto y flexible (Aguaded, 2005). Estos medios exponen una gr an o ferta formativa par a q ue el al umnado ex plore, descubra y aprenda por sí mismo (Lozana, 2019).

Se debe $\mathrm{n}$ tener $\mathrm{pr}$ esentes los cambios que se est án pr oduciendo, a un $r$ itmo vertiginoso, en la forma en que la sociedad consume y crea contenidos visuales (Ramos y Murillo-Ligorred, 2019). Los docentes tienen que se r conscientes de esta mediatización de I a so ciedad y, por el lo, $r$ esulta i mprescindible $t$ rabajar con el alumnado empleando como recurso la animación (Aragón y Patiño, 2010). No se trata de usa $r$ e stos $r$ ecursos como pr oducto de entretenimiento, si no d e ut ilizar I as animaciones como estrategia pedagógica y didáctica para mejorar y facilitar el proceso de enseñanza-aprendizaje; de ofrecer andamios a los estudiantes para promover una 
lectura co ntextualizada y si gnificativa co $n$ el obj etivo de $f$ avorecer el pasa je de I a mirada espontánea y rápida hacia una mirada detenida y abierta.

A la hor a de planificar las actividades de aprendizaje, es necesario tener en cuenta qué procesos mentales se activarán en el alumnado para facilitar la construcción de conocimientos nuevos y la reelaboración de sus estructuras de conocimiento.

Son varios los autores que ase guran q ue el u so de $r$ ecursos visuales en el aul a contribuye a una mejora en los procesos de ap rendizaje del alumnado (Alonso, 2005; García, 2012; López et al . 2014; Ll orente, 2000; Ll orent y M arín-Díaz, 2013; R igo, 2004). A su vez, el currículo de la ESO de la Comunidad Autónoma de Aragón. Dentro de las orientaciones metodológicas de la asignatura, recomienda la introducción del cine en el aul a co mo refuerzo al aprendizaje de la Geografía y la $\mathrm{H}$ istoria y co $\mathrm{n}$ el objetivo de contribuir a la alfabetización audiovisual del alumnado (Orden ECD/489/2016). En este marco, presentamos una experiencia desarrollada en torno al uso de recursos educativos audiovisuales, tales como cortometrajes o fragmentos de películas de animación.

El presente estudio realizó un experimento controlado sobre la validez didáctica de los recursos audiovisuales de animación centrando el análisis en un conjunto de grupos de primer ciclo de Educación Secundaria Obligatoria (ESO).

La investigación se desarrolló en el marco de la disciplina de Geografía e Historia, una asignatura obligatoria en primer ciclo de ESO. Los contenidos base de la experiencia fueron en pr imero de ESO del "bloque 1: E I m edio físico" y en se gundo fueron seleccionados contenidos del "bloque 3: La Historia" (Real Decreto 1105/2014).

En cu anto a I os materiales utilizados para el de sarrollo del trabajo se ce ntró en I os recursos audiovisuales de animación. Como condición previa fue imprescindible que el visionado del corto o fragmento estuviera integrado en el currículo del área, con el fin de ev itar i mprovisaciones que i mpidieran obt ener el $p$ rovecho $m$ áximo del $m$ aterial (Ruiz, 1994). 


\begin{tabular}{|c|c|c|c|c|c|}
\hline Título & Tipo & Producción & Curso & $\begin{array}{l}\text { Contenido } \\
\text { General }\end{array}$ & $\begin{array}{l}\text { Contenido } \\
\text { Específico } \\
\end{array}$ \\
\hline Lava & $\begin{array}{l}\text { Cortometraje } \\
\text { de animación }\end{array}$ & Pixar & \multirow{4}{*}{$1^{\circ} \mathrm{ESO}$} & $\begin{array}{l}\text { Los factores } \\
\text { que modelan el } \\
\text { relieve del } \\
\text { planeta }\end{array}$ & $\begin{array}{l}\text { Creación de los } \\
\text { volcanes }\end{array}$ \\
\hline Tarzán & \multirow{5}{*}{$\begin{array}{l}\text { Fragmento } \\
\text { de película } \\
\text { de animación }\end{array}$} & Estudios & & \multirow{3}{*}{$\begin{array}{l}\text { La diversidad } \\
\text { bioclimática }\end{array}$} & \begin{tabular}{|c|} 
Clima Ecuatorial \\
\end{tabular} \\
\hline El reyleón & & $\begin{array}{l}\text { Walt Disney } \\
\text { Feature } \\
\text { Animation }\end{array}$ & & & Clima cálido \\
\hline Pocahontas & & $\begin{array}{l}\text { Estudios } \\
\text { Walt Disney } \\
\text { Pictures }\end{array}$ & & & $\begin{array}{l}\text { Clima } \\
\text { continental }\end{array}$ \\
\hline Aladdín & & $\begin{array}{l}\text { Estudios } \\
\text { Walt Disney } \\
\text { Feature } \\
\text { Animation }\end{array}$ & & $\begin{array}{l}\text { El islam y el } \\
\text { proceso de } \\
\text { unificación de } \\
\text { los pueblos } \\
\text { musulmanes }\end{array}$ & $\begin{array}{l}\text { Configuración } \\
\text { de las ciudades } \\
\text { musulmanas }\end{array}$ \\
\hline $\begin{array}{l}\text { El } \\
\text { Jorobado } \\
\text { de Notre } \\
\text { Dame }\end{array}$ & & $\begin{array}{l}\text { Estudios } \\
\text { Walt Disney } \\
\text { Pictures }\end{array}$ & $2^{\circ} \mathrm{ESO}$ & $\begin{array}{l}\text { La Plena Edad } \\
\text { Media en } \\
\text { Europa (siglos } \\
\text { XI, XII y XIII). } \\
\text { Del feudalismo } \\
\text { al renacer de la } \\
\text { ciudad medieval }\end{array}$ & $\begin{array}{l}\text { Configuración } \\
\text { de las ciudades } \\
\text { medievales }\end{array}$ \\
\hline
\end{tabular}

Tabla1 Resumen de los recursos utilizados para el estudio

\section{Objetivos}

El objetivo específico de este estudio fue comprender cómo los estudiantes percibenlas actividades introductorias a los temas de Geografía e Historia mediante recursos audiovisuales.

A su vez, se p lantearon una serie de obj etivos generales como avanzar en el conocimiento de có mo planificar una clase que incorpore recursos visuales y conocer si estas actividades pueden ser utilizadas como puentes para fomentar la comprensión, motivación, atención y participación en las aulas de secundaria. 


\section{Metodología}

El em plazamiento del ca mpo de es tudio fue un co legio co ncertado de Zar agoza ubicado en un barrio del Casco Antiguo zaragozano, llamado San Pablo, y es considerada una de las zonas más diversas de la ciudad.

Se optó por un modelo de investigación etnográfico mediante el método de estudio de caso ( Velasco y Díaz de R ada, 2006 ) debi do a que el tema de es tudio est aba relacionado con la práctica educativa (Woods, 1998).

Se comenzó con la selección de la muestra que iba a formar parte de la investigación. Al $t$ ratarse de un di seño de $t$ ipo cu alitativo los investigadores decidieron a qué personas iba a observar y entrevistar, sin necesidad de recurrir a técnicas de muestreo aleatorio. En el estudio participaron 143 estudiantes, 74 alumnas y 69 alumnos, siendo 72 de primer curso de la ESO y 70 de se gundo curso. Los sujetos de la investigación estuvieron i mplicados de una forma nat ural en el fenómeno y t odoslo hi cieron de manera activa.

Siguiendo a Gutiérrez (2005) los procedimientos empleados para la recogida de datos fueron recursos para analizar e interrogar la realidad. Para el examen del contexto se utilizó la observación, notas de campo y registros, junto al análisis de documentos.

En las sesiones de aula se recurrió a la observación sistematizada (González, 2010). Se llevaron a ca bo multitud de notas de campo (descriptivas, textuales y aproximativas) junto co n un r egistro ane cdótico (Hammersley y Atkinson, 1994). Su redacción se realizó con el objetivo de ilustrar la información del relato oral y comportamiento no verbal de los participantes, para minimizar el nivel de deducción y facilitar su reconstrucción para su análisis.

Una primera codificación se trabajó con estas notas de campo ya que se trataban de documentos extensos y con descripciones minuciosas. Mediante su comparación se obtuvo una codificación inicial de tipo descriptiva (Gibbs, 2012).

La pr incipal her ramienta ut ilizada par a el cu estionamiento de I a r ealidad $f$ ue I as entrevistas semiestructuradas. Las preguntas de est a ent revista fueron diseñadas a partir de la organización de un primer sistema de categorías realizado en el proceso de 
clasificación inicial de los datos. Se consideró que la visión particular de los participantes en el caso era esencial para una buena investigación.

Las categorías, preparadas en esta fase, fueron organizadas en redes de relaciones, entre las categorías y la estructuración de los hallazgos (Varguillas, 2006).

Para el anál isis de l os dat os siguió un m étodo co mparativo co nstante ( Glaser y Strauss, 1967). Este proceso inductivo de anál isis de datos abordó la recopilación de información a través de preguntas y las notas de campo de los investigadores.

La comparación se realizó dentro del emplazamiento, es decir, se contrastaron sistemáticamente acontecimientos, situaciones o contextos desde el punto de vista de los objetivos de I a i nvestigación. A demás, se establecieron diferentes tipos de comparaciones en cada una de las etapas del análisis de los datos.

La teoría se desarrolló mediante el registro sistemático de información de ca mpo. No obstante, antes los investigadoresreflejaron en un diario el proceso de codificación y creación de categorías y temas. Para su realización utilizó la técnica que plantea Flick (2012) de realización de preguntas básicas (qué, quién, cómo, cuándo, cuánto, por qué, para qué y por quién), para conseguir el estudio de los textos de manera regular.

Para el análisis se realizaron reiteradas reducciones de datos. Se comenzó con una extracción de uni dades de análisis del contexto para obtener una codificación abierta (códigos ad hoc) (Flick, 2015). Para este examen se combinó el proceso con la herramienta co mputacional A TLAS.ti, que favoreció la r evisión si multánea de un a amplia gama de materiales y facilitó su organización y clasificación. Con la ayuda de esta herramienta se buscaron patrones y relaciones entre los datos obtenidos.

\section{Resultados}

Las categorías que se analizaron en relación al uso de recursos audiovisuales como elemento de apoyo en la introducción de los bloques temáticos del área de Geografía e Historia en primer ciclo educación secundaria fueron:

- $\quad$ Mejora en la comprensión inicial del contenido conceptual del tema 
- $\quad$ Aumento del grado de motivación del alumnado frente a los nuevos contenidos presentados

- $\quad$ Predisposición en una participación activa en la sesión de la clase introductoria del tema

- Mejora de la capacidad creativa e imaginativa en los estudiantes

- $\quad$ Activación de los contenidos previos

A continuación se exponen los resultados de las respuestas de los estudiantes durante las entrevistas. S e r ealiza de $\mathrm{m}$ anera $\mathrm{g}$ lobalizada $\mathrm{m}$ ediante di ferentes gráficos, e $\mathrm{n}$ primer lugar, ordenadas las respuestas por cursos y, posteriormente, por ciclo.

En relación a la ayuda que supuso los recursos audiovisuales para la comprensión de los nuevos contenidos pr esentados, el al umnado de a mbos cursos lo $v$ aloró positivamente y a que consideraron que contribuía en la i nterpretación de aq uellos conceptos que eran más abstractos, como por ejemplo la creación de un v olcán. El uso de estos recursos favoreció la comprensión por parte de los estudiantes y facilitó la posterior explicación del docente.

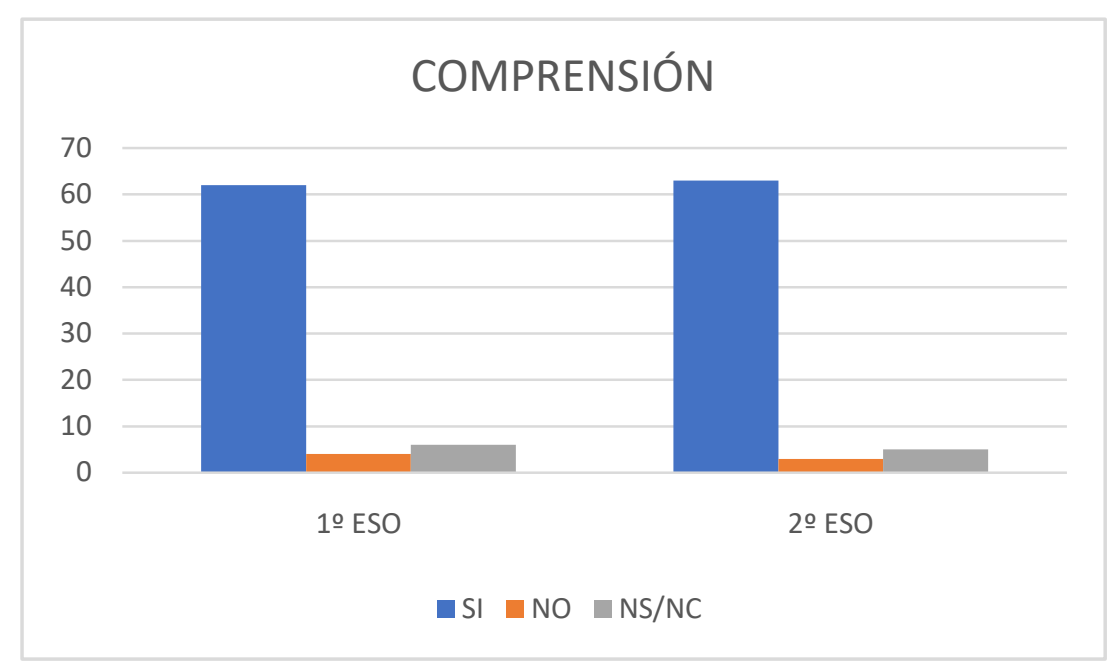

Gráfico 1: Resultados comparativos en tre $1^{\circ}$ y $2^{\circ}$ de la ESO obtenidos de I as ent revistas en relación a I a c ategoría r elacionada c on I a m ejora en l a c omprensión i nicial del c ontenido conceptual del tema 
En las entrevistas los estudiantes destacaron que este sistema de trabajo había hecho que mostraran una mayor motivación durante la introducción al tema trabajado. Se debe dest acar que el alumnado co nsideró que su gr ado de m otivación ha cia el desarrollo de I os contenidos aumenta. El al umnado de pr imer curso expusó que les ayuda a t ener una act itud favorable para aprender los contenidos y tener un $\mathrm{m}$ ayor interés por el área. Los estudiantes de segundo, en los que la percepción de la motivación fue menor, puntualizando en I as entrevistas que fue debi do a que los recursos audiovisuales ya los utilizaban también en primero y por tanto el factor de la novedad era menor.

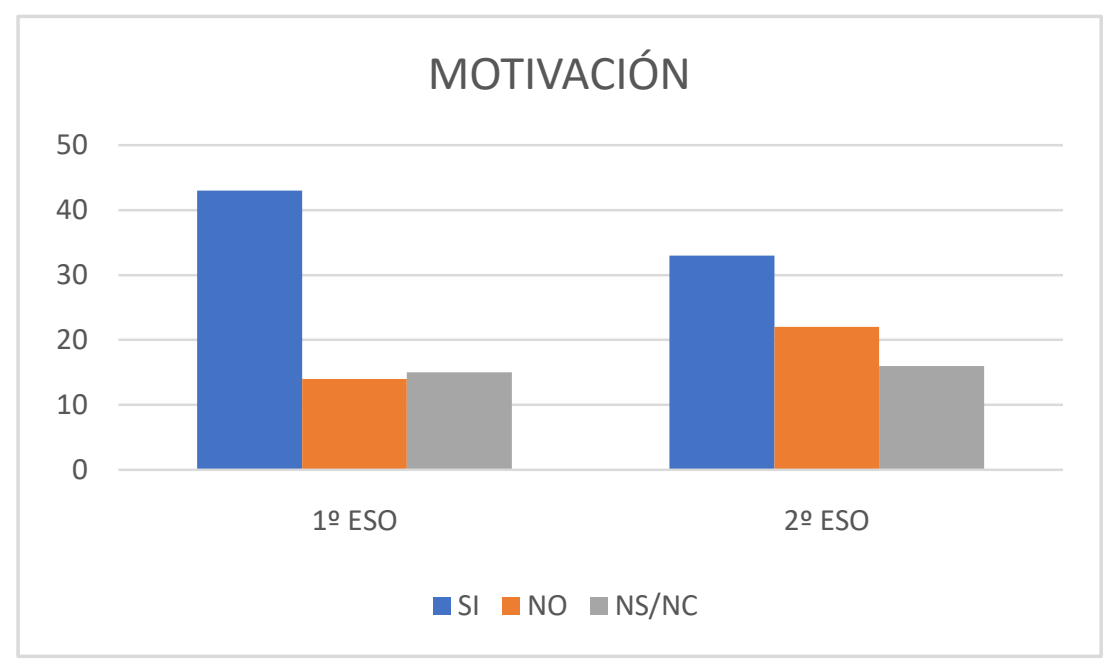

Gráfico 2: Resultados comparativos en tre $1^{\circ}$ y $2^{\circ}$ de la ESO obtenidos de las ent revistas en relación a la categoría relacionada con la percepción de los estudiantes con el aumento del grado de motivación frente a los nuevos contenidos presentados

Los entrevistados consideraron que, en la fase inicial de introducción al tema, la participación co nsistía principalmente en ex poner l as dudas o co ntestar al as preguntas que el doce nte r ealizaba. Elal umnado de pr imero manifestó que I os recursos audiovisuales los animaban desa rrollar $u$ na par ticiparon $m$ ás activa $q$ ue cuando se ut ilizaban ot ro $t$ ipo de $r$ ecursos. Durante l a obse rvación en el aul a se destacó que I os estudiantes de est e cu rso par ticipaban de forma di námica respondiendo de $\mathrm{m}$ anera $\mathrm{m}$ ayoritaria a $\mathrm{I}$ as preguntas que realizaba el profesor. $\mathrm{A}$ pesar de ello es uno de los aspectos que más le cuesta a la hora de iniciar un nuevo tema en cl ase. Los estudiantes de se gundo consideraron que el uso de $r$ ecursos 
audiovisuales no les hace participar de una manera di ferenciada. A pesar de es ta percepción por pa rte de I al umnado de se gundo l a obse rvación realizada en el aula también de terminó un a par ticipación act iva. $\mathrm{E} \mathrm{nI}$ as entrevistas se dest acó I a importancia de la actitud de los docentes en el aula. Consideraron que sus profesores tienen una act itud muy positiva y abierta ante sus dudas y preguntas y eso es muy importante a la hora de fomentar su participación.

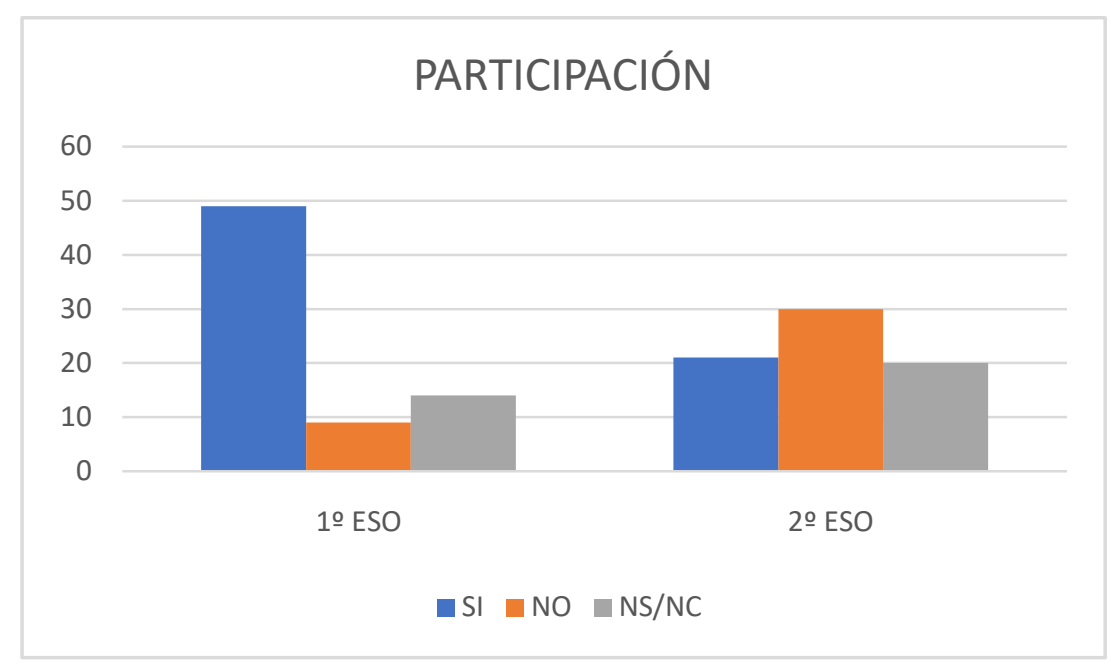

Gráfico 3: Resultados comparativos en tre $1^{\circ}$ y $2^{\circ}$ de la ESO obtenidos de I as ent revistas en relación a la c ategoría relacionada $\mathrm{c}$ on la $\mathrm{p}$ ercepción de l os estudiantes con gr ado de participación del alumnado en las sesiones introductorias al tema.

Casi la totalidad de los discentes estimó que el uso de este tipo de recursos como un elemento dinamizador de la metodología en la enseñanza de Geografía e Historia, mejorando su creatividad e i maginación en I as fase iniciales de presentación de I os contenidos.Tanto los estudiantes de primer curso co mo los de se gundo concluyeron que la i magen ani mada e ra un buen recurso para ay udarles a imaginar de manera mucho más concreta algunos escenarios que, incluso por medio de las imágenes, les resulta co mplejo. Por medio de I os recursos audiovisuales les ayuda a co mprender, explicar y recrear escenarios y situaciones cercanas. Ellos consideran que están muy familiarizados con este tipo de imágenes y por ellos les cuesta poco esfuerzo reconocerlas y asociarlas la realidad. 


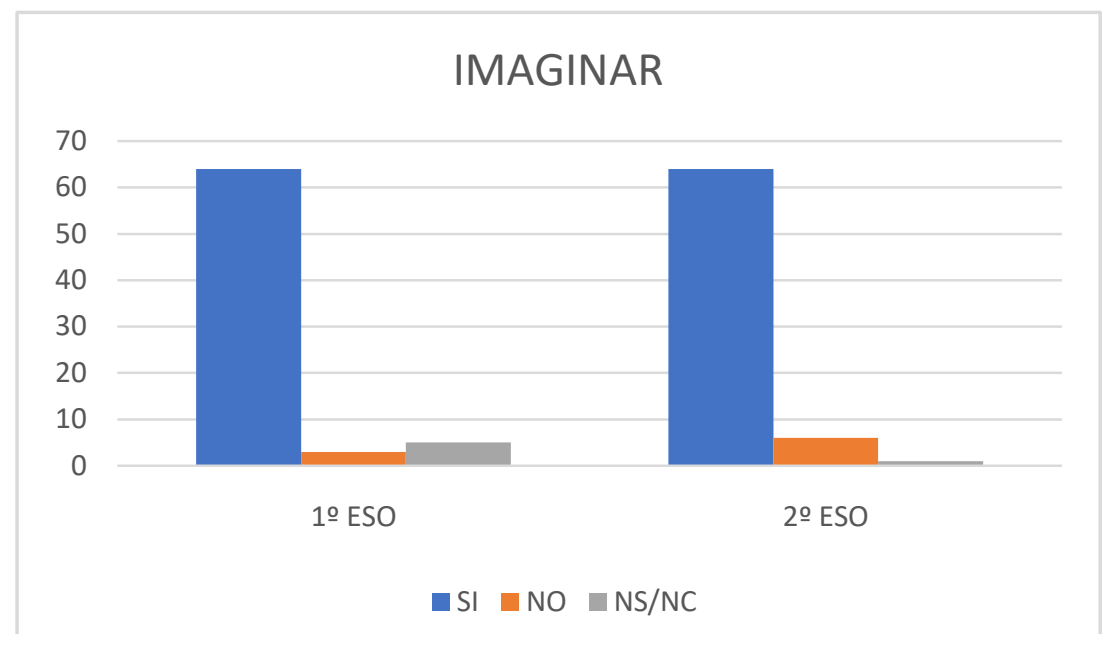

Gráfico 4: Resultados comparativos en tre $1^{\circ}$ y $2^{\circ}$ de la E SO obt enidos de I as ent revistas en relación a la c ategoría r elacionada c on l a c apacidad de i maginar s ituaciones gr acias a l os recursos audiovisuales.

Los estudiantes explicaron que el tener referentes visuales de los contenidos facilita la recreación de espacios y ayuda a ubicarse. Este hecho les ayudó a activar sus conocimientos previos.Además, asocian la importancia de i maginar los contextos con el de ser capaces de recordarlos durante mayor tiempo. El alumnado consideró que el visualizar los contenidos es uno de I os aspectos importantes para su co rrecta comprensión y la causa para recordarlos en el tiempo. Consideran que les resulta más sencillo recordar las imágenes que las palabras y por tanto los conceptos expuestos permanecen mucho $\mathrm{m}$ ás tiempo en su $\mathrm{m}$ emoria en co mparación co $\mathrm{n}$ aq uello introducido de forma oral o escrita. 


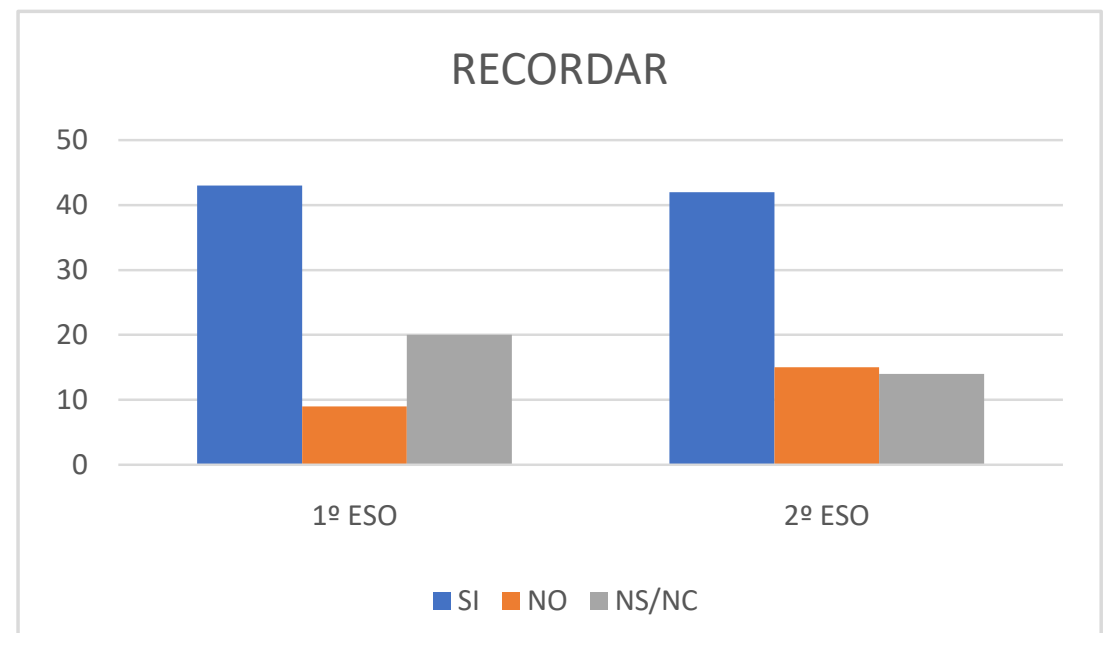

Gráfico 5: Resultados comparativos en tre $1^{\circ}$ y $2^{\circ}$ de la ESO obtenidos de I as ent revistas en relación a la categoría relacionada con la percepción de los estudiantes respecto al tiempo en el que recuerdan los conceptos trabajados.

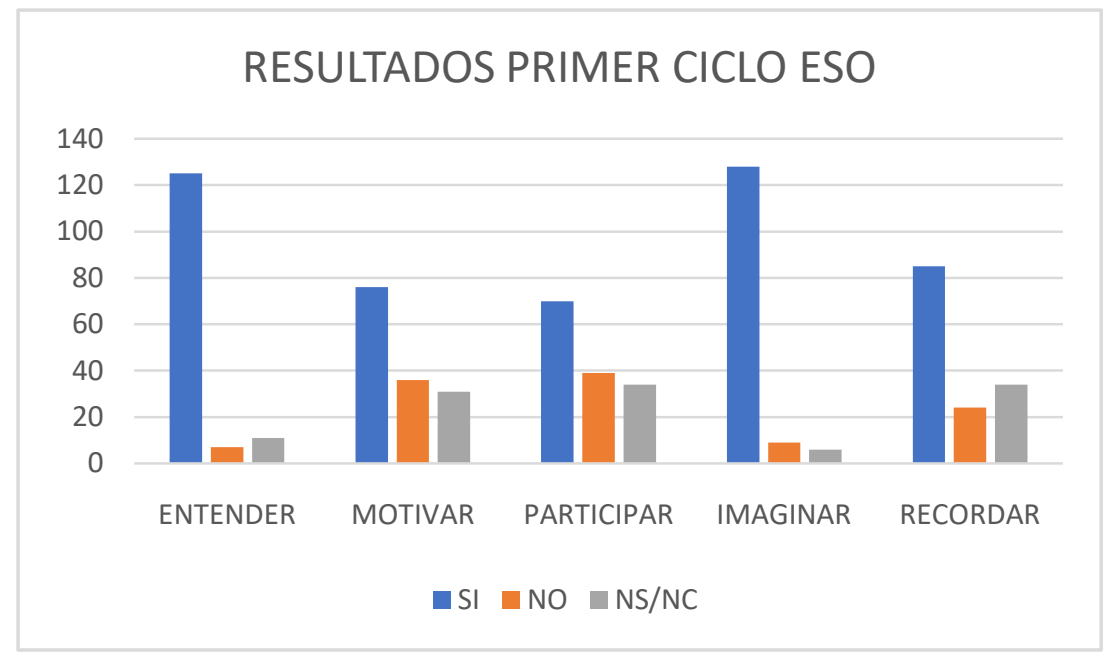

Gráfico 6: Resultados totales, de primer ciclo de ESO, agrupados por categorías.

\section{Discusión}

Los estudiantes que participaron en este estudio, al igual que en el estudio de López y otros (2014), ace ptaron y vieron el material audiovisual utilizado para la introducción de los temas como útil. 
Las películas de animación muestran la representación de I a i magen mental que el alumnado tienen de la realidad, por su temática y estilo, la banda sonora, el montaje, el co lor, I a I ínea, el esp acio, et c. (Ivelic, 2017). E sto I es permite ubi carse espacialmente y co mprender I os contenidos. Los estudiantes aprenden de forma principalmente visual, prefieren aprender en el momento, es decir, necesitan acceder a la i nformación que pr ecisan de f orma i nmediata y a que est án aco stumbrados a la gratificación instantánea (Granado, 2010).

Brewster y Fager (2000)resaltan que el compromiso y la motivación por parte de los estudiantes es lo que posibilita el alcance de logros relevantes. Los estudiantes que no están motivados para participar en el aprendizaje es poco probable que tenga éxito.

Por medio de la selección de fragmentos que ilustren conceptos curriculares se logra evitar una actitud pasiva frente a la pantalla (Ivelic, 2017). El docente debe lograr que el al umnado diferencie entre los recursos audiovisuales como medio de ocio, donde predomina la inactividad y sobreestimulación, y su empleo como recurso didáctico.

A pesar de ser un gran consumidor de imágenes, tanto fijas como en movimiento, los estudiantes todavía no están habituados a aprender de ellas, ni las consideran fuentes serias de i nformación út il, faltando ci erta em ancipación en el los (Rancière, 2010 ). Desde I os entornos educativos se debe I ograr que se u tilice est e si stema de comunicación simbólico para que el alumnado comprenda y participe, pase de mirar a actuar (Aguirre, 2015), de los intercambios comunicativos y productos culturales de su entorno (Llorente, 2000).

Los recursos audiovisuales en el aul a se deben em plear de manera e ficaz par a fomentar la proactividad de los discentes, ya que requiere de una par ticipación activa del est udiante, de su i nteracción co $\mathrm{n} I$ os medios y $\mathrm{m}$ ateriales y co $\mathrm{n}$ el $\mathrm{r}$ esto de compañeros y compañeras (Ramos y Moreno, 2020). Mientras que la televisión se centra en el espectáculo y en el entretenimiento, alejándola del carácter formativo que, por otro lado, sí tiene la educación, esta centra su trabajo en una perspectiva histórica, que nece sita de una co nstante ac tualización para ev itar I a obso lescencia de I os contenidos (Aguaded, 1997).

A pesar de q ue en I a e tapa de pr imer ci clo de I a ESO fomentar Ia participación del alumnado es complejo, por $\mathrm{m}$ edio de $\mathrm{I}$ os recursos audiovisuales hace $\mathrm{q}$ ue, la 
presentación de I os contenidos sea más dinámica y facilita la comunicación (Seva y Vera, 2010). En este sentido, es importante tener en cuenta que planificar actividades partiendo del si mple he cho de q ue l a se cuencia t enga un "carácter a ctivo" no es suficiente. Las actividades que se $\mathrm{p}$ ropongan al al umnado deben $\mathrm{p}$ romover un a intensa actividad de reflexión sobre los aprendizajes que se trabajan y esta actividad ha de ser directamente proporcional a la complejidad y dificultad de su comprensión.

Debido a la emoción que los dibujos animados provocan en el alumnado, gracias a su sencillo I enguaje y a s us coloridas imágenes, $r$ esultan un elemento $m$ uy atractivo (Marín y González, 2011).

El valor estético integra tanto lo sensible como lo inteligible, lo que sirve de estimulante para los estudiantes debido a que desarrolla su intelecto, su imaginación y su sensibilidad. Muchas películas de animación presentan contenidos con un gran poder educativo y de influencia social, además, es de logra captar su atención, les permite aprender a través de la imaginación, la fantasía y la ilusión de forma lúdica (González et al., 2018).

Cuando los discentes se enfrentan a la presentación un nuevo contenido, la primera actividad $\mathrm{m}$ ental $\mathrm{q}$ ue pondr á en funcionamientos será $\mathrm{l}$ a de acc eder a su $\mathrm{s}$ conocimientos previos. Sin embargo, en el momento en que dichos conocimientos no sean suficientes o no respondan adecuadamente al nuevo conocimiento o situación de aprendizaje, será cuando activará otro tipo de procesos mentales que le ayudarán a hacer frente al desajuste producido por el conflicto cognitivo.

La presencia de pi stas visuales ayuda a los estudiantes a recopilar el conocimiento previo que habría sido menos accesible si sólo hubieran estado trabajando con fuentes verbales o escritas (Barton y Levstik, 2008).

En I a presentación de nuevos conceptos teóricos se debe I ograr que el al umnado integre los nuevos contenidos a las estructuras cognitivas ya existentes y esto exige, la realización de actividades que le ayuden en este proceso, de acuerdo con su nivel de desarrollo cognitivo, en relación a la complejidad del nuevo contenido o aprendizaje. Por este motivo, las actividades que se proponen durante esta la secuencia inicial deben ser diversas y estar enfocadas a trabajar cada uno de los diferentes procesos mentales que los estudiantes deben poner en funcionamiento durante el proceso de 
aprendizaje.Si la actividad planteada tiene relación con la cotidianeidad del alumnado, como es el visionado de unrecurso audiovisual, se pueden activar los conocimientos previos y los vuelva a poner en funcionamiento.

\section{Conclusiones}

El uso de material audiovisual como apoyo a la introducción de los temas supone un buen complemento para reforzar la comprensión de la materia siempre que su selección y planificación sea correcta y complemente las explicaciones del docente. Es imprescindible un trabajo previo del doce nte para l a selección de un material audiovisual adecu ado q ue facilite su co ntextualización dent ro de I a di námica de I a clase y de los contenidos curriculares.

Las actividades planteadas por $\mathrm{m}$ edio de recursos audiovisuales durante $\mathrm{I}$ a introducción de los temas no deben responder solo al hecho de que el alumnado se mantenga "activo", si no q ue deben se $r$ di señadas teniendo en cu enta el t ipo de contenido que se trabajará y qué procesos mentales se ac tivarán durante su realización para promover un verdadero aprendizaje significativo.

Es importante reflexionar so bre el potencial de I a cultura audiovisual y el papel que desempeñan en I a actualidad dent ro de I as aulas. Es una he rramienta que pe rmite introducir co ntenidos curriculares de Geografía y la Historia de forma m otivadora lo que permite un posterior análisis y profundización de los temas.

Por todo ello, la puesta en funcionamiento de habilidades, co mo la observación, el análisis e i mplementación de es trategias de a prendizaje, ay udarán al al umnado a reestructurar y ampliar sus conocimientos para, finalmente, conseguir la acomodación del nuevo aprendizaje.

\section{Agradecimientos}

Grupo de investigación ARGOS S50_17R (Gobierno de Aragón), Instituto de Investigación de Ciencias Ambientales de Aragón (IUCA) y Red-14 de investigación en enseñanza de las ciencias sociales (RED2018-102336-T), MINECO/AEI. 


\section{Referencias}

Aguirre, I . ( 2015). H acia una nar rativa de I a em ancipación y l a s ubjetivación des de una educación del arte basada en la experiencia. Docencia, 57, 5-15

Aguaded, J. I. (1997). La televisión en el nuevo diseño curricular español. Comunicar, 8, 97-109.

Aguaded, J . I. ( 1999). P rácticas de ut ilización di dáctica de I a televisión e n Ias aulas. A ula de encuentro. Revista de investigación y comunicación de experiencias educativas, 3, 1333.

Aguaded, J. I. (2005). Enseñar a ver la televisión: un as pecto necesario y posible. Comunicar, 25, 51-55.

Alonso, J . (2005). Motivación para el a prendizaje: pe rspectiva de los al umnos. En VV.AA., La orientación en centros educativos (pp. 209-242). Ministerio de Educación y Ciencia.

Ambrós, A. y Breu, R. (2011). Educar en medios de comunicación. Graó.

Aragón, P. A. y Patiño, M. B. (2010). Dibujos animados en la enseñanza. Góndola, Enseñanza y Aprendizaje de las ciencias (Bogotá, Colombia), 5(1), 38-42.

Barton, K. C. y Levstik, L. S. (2004).Teaching history for the common good. Lawrence Erlbaum Associates Publishers.

Brewster, C. y Fager, J. (2000). Increasing student engagement and motivation: From time-ontask to homework. Northwest Regional Educational Laboratory.

Caeiro Rodríguez, M., Callejón Chinchilla, M. y Chacón Gordillo, P. (2021). El diseño de métodos poéticos y autopoéticos en Educación Artística: articulando metodologías y metodografías. Arte, Individuo $\quad Y \quad$ Sociedad,33(3), $769 \quad-790$. https://doi.org/10.5209/aris.69263

Cislaghi, A . ( 2020). I mágenes en I a práctica de I a ens eñanza. Actas de diseño 31, 8 1-87. https://pub.palermo.edu/ojs/index.php/actas/article/view/2088/5840

Dewey, J. (2008). El arte como experiencia. Paidós.

Espinar, E. y Vigueras, J . (2020). E I a prendizaje e xperiencial y s u i mpacto en I a educación actual. Revista Cubana de Educación Superior, 1-4.

Flick, U . ( 2012). I ntroducción a I a c olección: I nvestigación cualitativa. E n M. Angrosino, Cualitativa, Etnografía y observación participante en investigación (pp. 9-13). Morata.

Flick, U. (2015). El Diseño de Investigación Cualitativa. Morata.

García, A., T ur-Viñes, V. y Pastor, Y. (2018). Consumo mediático de adolescentes y jóvenes. Noticias, c ontenidos aud iovisuales y m edición de a udiencias. Icono 14, 16(1), 22 -46. https://doi.org/10.7195/ri14.v16i1.1101

García, C. (2012). ¿Qué puede aportar el arte a la educación? El arte como estrategia para una educación inclusiva. ASRI - Arte y Sociedad. Revista de Investigación(1).

Gibbs, G. (2012). El análisis de datos cualitativos en investigación Cualitativa. Morata. 
Glaser, B. G. y Strauss, A. L. (1967). The discovery of grounded theory. Aldine.

González, G . (2010). L a transición en tre teoría y c ampo de i nvestigación en didáctica de las ciencias sociales. En R. Ávila, P. Rivero y P. Domínguez, Metodología de investigación en Didáctica de las Ciencias Sociales (pp. 167-173). Institución "Fernando el Católico"(C.S.I.C.).

González, M. C., Gómez, E. M. y Domínguez, M. C . (2018). Cine de an imación y educación. Modelos de pe lículas de ani mación y sus virtualidades ed ucativas. RELAdEI. Revista Latinoamericana de Educación Infantil, 7, 99-126.

Granado, J. (2010). Un instrumento de análisis para la investigación del uso de las tic-tac en la enseñanza de la geografía par a el d esarrollo s oscenible. En R. Á vila, P. Rivero y P. Domínguez, Metodología de investigación en Didáctica de las Ciencias Sociales (págs. 313-325). Institución "Fernando el Católico"(C.S.I.C.). AUPDCS

Gutiérrez, R . ( 2005). L os es tudios de c asos: una opc ión $m$ etodológica para i nvestigar I a educación artística. En R. Marín-Viadel, Investigación en Educación Artística (págs. 151174). Universidad de Granada.

Hammersley, M. y Atkinson, P. (1994). Etnografía. Métodos de investigación. Paidós Básica.

Ivelic, R. (2017). Televisión infantil y dibujos animados. Revista Aisthesis, 55-63.

Llorent G arcía, V . J . y Marín-Díaz, V . (2013). La integración d e l os di bujos ani mados en e I currículo de Educación Infantil. Una propuesta teórica. REICE. Revista Iberoamericana sobre Calidad, Eficacia y Cambio en Educación, 12 (1), 73-82.

Llorente, E. (2000). Imágenes en la enseñanza. Revista de Psicodidáctica 9, 1-19.

Lois, C . y Hollman, V . (2013). Geografía y Cultura Visual. Los usos de las imágenes en las reflexiones sobre el espacio. Prohistoria Ediciones.

López, D., García, M., Campello, L., Formigós, J. A., Lax, P., Fernández-Sánchez, L. y Maneu, V. (2014). Uso de $m$ aterial audiovisual como apoyo en las clases teóricas. En VV.AA., XII Jornadas de Redes de Investigación en Docencia Universitaria. El reconocimiento docente: innovar e investigar con criterios de calidad (págs. 122-131). U niversidad de Alicante.

López, R. y De la C aba, M. (2010). Met odología de investigación para la evaluación de competencias de autonomía y ciudadanía en relación con el afrontamiento del conflicto entre iguales. En R.M. Ávila, P. Rivero y P.. Domínguez, Metodología de investigación en Didáctica de las Ciencias Sociales (pp. 263-271).Institución "Fernando el Católico"AUPDCS

Lozana, P. (2019). El uso de medios a udiovisuales en el aula. Revista: Atlante. Cuadernos de Educación y Desarrollo. https://www.eumed.net/rev/atlante/2019/10/mediosaudiovisuales-aula.html

Marín, V. y González, I. (2011). La televisión ¿medio para el desarrollo de la Educación Infantil? Educatio Siglo XXI, 29(1), 345-360.

Orden E CD/489/2016, de 26 d e m ayo, p or l a que s e apr ueba el c urrículo de l a E ducación Secundaria Obligatoria y se autoriza su aplicación en los centros docentes de la 
Comunidad Autónoma de Aragón. Boletín Oficial de Aragón. DEPARTAMENTO DE EDUCACIÓN, CULTURA Y DEPORTE, 2 de junio de 2016, núm. 105, pp. 12859- 12885

Rancière, J. (2010). El espectador emancipado. Manantial.

Ramos, M. y Moreno, M. (2020). La influencia de los recursos audiovisuales para el aprendizaje autónomo en el a ula. Anuario Electrónico de Estudios en Comunicación Social "Disertaciones", https://revistas.urosario.edu.co/xml/5115/511562674008/html/index.html

13(1).

Ramos, N. y Murillo-Ligorred, V. (2019). La cinematografía artística como recurso didáctico para la expresión visual y plástica: una ex periencia doc ente c on el a lumnado de I grado de maestro en educ ación i nfantil. ENSAYOS, Revista de la Facultad de Educación de Albacete, 34(1), 53-67.

Real Decreto 1105/2014, de 26 de diciembre, por el que se establece el currículo básico de la Educación Secundaria Obligatoria y del Bachillerato. Boletín Oficial del Estado. Madrid, 3 de enero de 2015, núm. 3, pp. 297-304.

Rigo, D. (2004). Aprender y ens eñar a través de imágenes. Desafío e ducativo. ASRI - Arte y Sociedad. Revista de Investigación, 6, 1-9.

Ruiz, F. (1994). Cine y enseñanza. Comunicar 3, 74-80.

Seva, F. S. y Vera, M. (2010). La práctica docente en las ciencias sociales: un análisis cualitativo. En R. Ávila, P. R ivero y P. D omínguez, Metodología de investigación en Didáctica de las Ciencias Sociales (pp. 175 -183). Institución "Fernando el C atólico"AUPDCS

Varguillas, C. (2006). El uso de ATLAS.ti y la creatividad del investigador en el análisis cualitativo de contenido Upel. Instituto pedagógico rural de Mácaro. Revista de educación, 12, 7387.

Velasco, H. y Díaz de Rada, A. (2006). La lógica investigación etnográfica. Un modelo de trabajo para etnógrafos de escuela. Trolla.

Woods, P. ( 1998). La escuela por dentro. La etnografía de la investigación educativa. Paidós/MEC.

\begin{tabular}{l} 
Publicado bajo licencia internacionalCreative Commons Attribution-NonCommercial-ShareAlike4.0 \\
(CC-BY-NC-SA 4.0). Se permite copiar, usar, distribuir, transmitir y exhibir públicamente, \\
siempre que: i) se reconozca la a utoría y la fuente original de publicación (revista, editorial y \\
URL del trabajo); ii) no se utilice con fines comerciales; iii) se mencione la existencia y \\
especificaciones de esta licencia. \\
\hline
\end{tabular} 